\title{
On an application of node MCU Esp8266 in opening and closing the laboratory door - online practice
}

\author{
Nguyen Tai Tuyen *, Nguyen Quang Ngọc and Nguyen Xuan Hung \\ Posts and Telecommunications Institute of Technology Hanoi City, Vietnam. \\ Global Journal of Engineering and Technology Advances, 2021, 09(03), 086-091
}

Publication history: Received on 20 November 2021; revised on 23 December 2021; accepted on 25 December 2021

Article DOI: https://doi.org/10.30574/gjeta.2021.9.3.0174

\begin{abstract}
This paper presents an application of ESP8266 node MCU in building a networked laboratory door opening and closing system (NLDOC system). The article mentions the function of the ESP8266 node MCU [1-3], and the Arduino application to serve as the basis for the development of an application that connects computers and smartphones [5-6], allowing to control the door latch of the practical labs remotely via Wi-Fi combined with security monitoring through the camera system [4].
\end{abstract}

Keywords: NLDOC system; On - off systems; ESP8266 connects Computer; PTIT

\section{Introduction}

The remote opening and closing system via computer network will contribute to modernizing the management of the practical laboratory at the practical laboratory center, Posts and Telecommunications Institute of Technology, Hanoi campus. With the scale of practical laboratories equipped with high configuration computers, network equipment systems and 4G, 5G Electronics and Telecommunications Labs are used for research and training. Therefore, it is very necessary to manage and monitor the opening and closing of doors remotely through the application of technology for practical laboratories, a synchronous way of management with high efficiency.

In order to contribute to mastering technology for management, gradually modernizing the management of the Lab, the group of lecturers from the practical laboratory center conducted a test of the monitoring model, opened the door of the laboratory, remote operation via the Node MCU Amica [6] application network in establishing a Wi-Fi connection point with computers and Smartphones to control and monitor the process of opening and closing the door remotely instead of the traditional way of management before, where the manager had to go to each room to open the door for lecturers and students.

\section{Node MCU Amica Overview}

\subsection{ESP8266 node MCU}

ESP8266 is a microcontroller that allows to control electronic devices, integrated with programmable $2.4 \mathrm{GHz}$ wi-fi, creating an application development environment on hardware using opensource code built on the chip system (SoC) with the basic components of a computer such as: CPU, RAM, Wi-Fi card, even a modern operating system and SDK [6].

\footnotetext{
* Corresponding author: Nguyen Tai Tuyen

Posts and Telecommunications Institute of Technology Hanoi City, Vietnam. 


\subsection{Specifications}

- Wi-Fi: 2.4GHz supports $802.11 \mathrm{~b} / \mathrm{g} / \mathrm{n}$ standard

- $\quad$ Operating voltage: $3.3 \mathrm{~V}$

- Input voltage: $5 \mathrm{~V}$ via USB connector

- $\quad$ Number of I/O pins: 11 (all I/O pins have Interrupt/PWM/I2C/One-wire, except D0)

- Number of Analog Input pins: 1 (maximum input voltage 3.3V)

- Flash Memory: 4MB

- Communication: Micro USB cable (using the same phone charging cable)

- $\quad$ Security support: WPA/WPA2

- Integrated TCP/IP protocol

- $\quad$ Programming in languages: $\mathrm{C} / \mathrm{C}++$, python, ...

\subsection{Arduino and ESP 8266 connection diagram in door opening and closing}

- $\quad$ Display feedback signal: 0/1 (T/F);

- Display relay status ON and OFF.

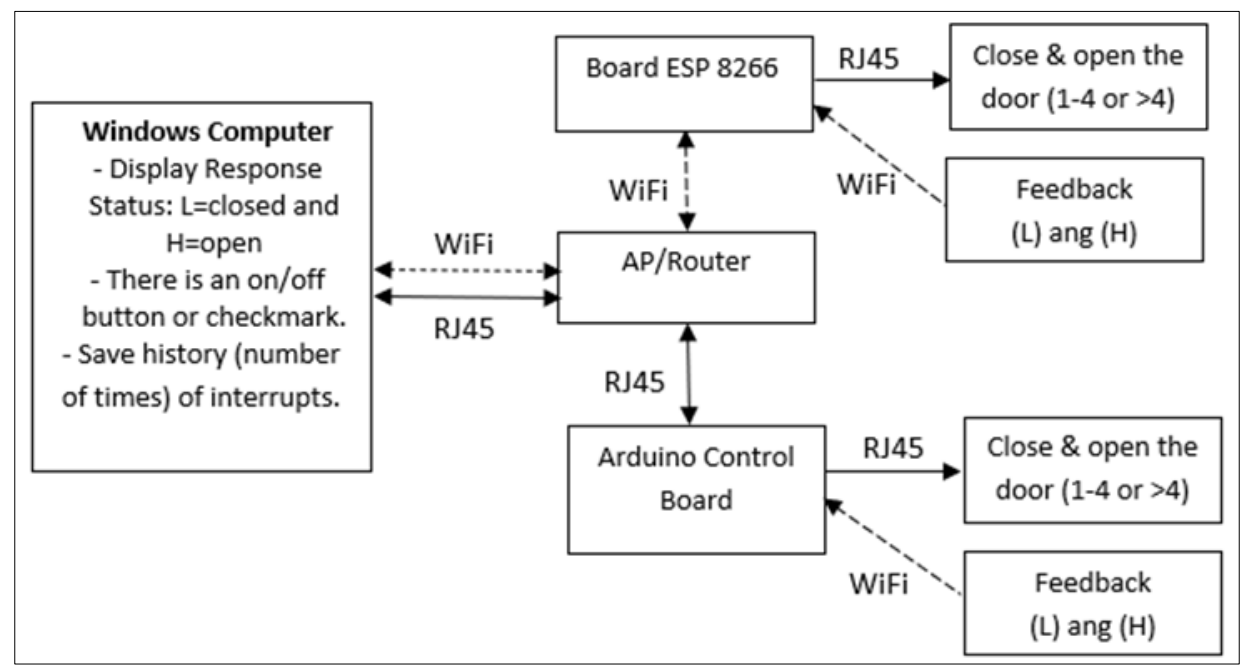

Figure 1 Arduino and ESP 8266 in a door opening system

\section{Electromagnetic door latch lock}

Depending on the specific application, we can choose between normally closed or normally open latches.

\subsection{Normally closed latch lock (Open when powered)}

The normally closed latch lock is a type of latch lock with the function of closing the door when the power fails, that is, the lock will automatically close when the power supply to the lock is lost. Normally closed locks are often used in units that need high security, safety is a top priority.

The lock that normally closes is similar in structure to other common latch locks currently on the market. The normally closed latch lock consists of 2 parts, the lock body and the magnetic suction pad to suck the latch when closing the door. Normally closed locks also have an opening and closing time adjustment part right on the lock body so that users can adjust the appropriate time.

\subsection{Normally open electromagnetic locking latch type (closes when powered)}

Normally open lock in principle of structure is similar to other common latch locks currently on the market. The normally open latch lock consists of 2 parts, the lock body and the magnetic suction pad to suck the latch when opening the door latch. Normally open locks also have an opening and closing time adjustment part right on the lock body so that users can adjust the appropriate time. 


\section{Design of remote door opening and closing system using ESP8266 node MCU}

\subsection{Device pairing diagram}

In (Figure 2), block 1 is considered as the center of the system, designed to pair 4 relays linked to the ESP8266 node MCU module that receives commands from the computer to control the opening and closing of the 4 labs; block 2 including computers and smartphones to control the system through the web interface on the computer and the app on the smartphone; block 3 converts AC 220v to DC 12v supplying power for blocks 1 and 8 , and at the same time recharges backup battery block 5; block 4 is the mains power supply to the system through the AC/DC converter circuit; blocks 5 and 6 are a backup battery with the function of supplying power to the system when the circuit breaker is lost or cut; block 7 broadcasts Wi-Fi Internet connection for block 5 if this block is set up to connect to the Internet; block 8 is magnetic locking latch with the function to keep the door locked securely.

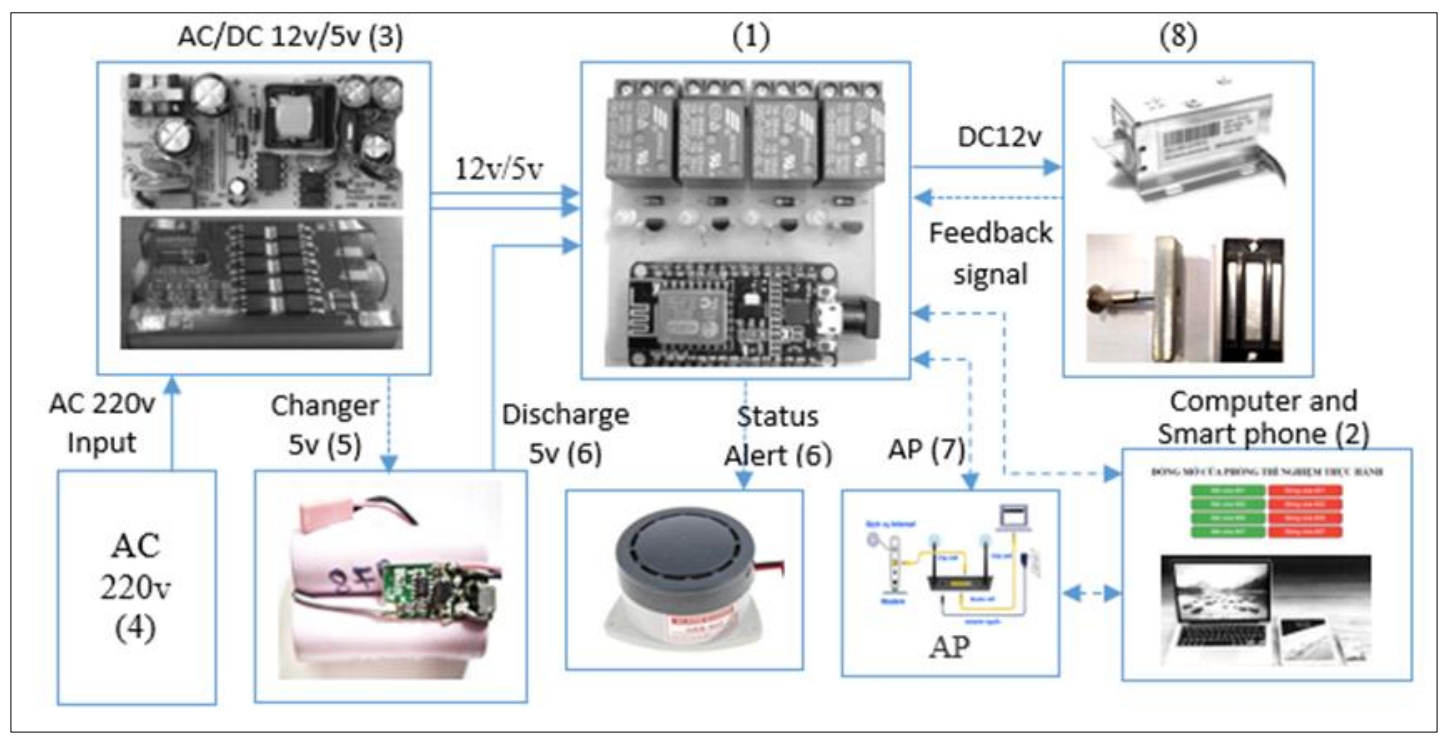

Figure 2 Diagram of opening and closing system of practice room

\subsection{Control program of the door opening and closing}

\#include <ESP8266WiFi.h>

\#include $<$ Wi-FiClient.h $>$

\#include <ESP8266WebServer.h>

\#include <ESP8266mDNS.h>

\#define TB1 16

\#define TB2 5

\#define TB3 12

\#define TB4 13

IPAddress apIP $(192,168,6,1)$;

ESP8266WebServer server(80);

String webPage $=$

\{

"<!DOCTYPE html>"

"<html>"

"<head $>$ "

" <meta http-equiv='Content-Type' content='text/html; charset=utf-8'>"

$"<$ title $>$ TRUNG TAM THI NGHIEM THUC HANH $</$ title $>"$

" <meta name='viewport' content='width=device-width, initial-scale=1'>"

"<style>"

".b\{width: 100px;height: 40px;font-size: 21px;color: \#FFF; background-color:\#4caf50;border-radius: 10px;\}" 
".t\{width: 100px;height: 40px;font-size: 21px;color: \#FFF;background-color:\#f44336;border-radius: 10px;\}"

"</style $>$ "

$"</$ head $>$ "

"<body $>$ "

"<div style='width: 330px; height: auto;margin: 0 auto;margin-top: 70px'>"

"<h1 align='center'>DONG MO CUA PHONG THUC HANH $</$ h1 $>$ "

"<table align='center'>"

" $<$ tr $>"$

...

void TrangChu(0

\{

server.send(200, "text/html", webPage);

\}

Serial.begin(9600);

Serial.println();

Serial.println();

Serial.print("Connecting to ");

WiFi.softAPConfig(apIP, apIP, IPAddress(255, 255, 255, 250));

WiFi.softAP("CO_LAB ","......");

...

server.on("/", TrangChu);

server.on("/Mở 607", Mo_607);

server.on("/Đóng 607", Dong_607);

-..

server.begin 0 ;

\}

void loop()

\{

server.handleClient(); \}

\subsection{Control and locking system}

Below is a remote control system for opening and closing the door via the network, assembled in a $200 \times 120 \times 75 m m$ shrink plastic box (Figure 3a) and locking latch (Figure 3b).
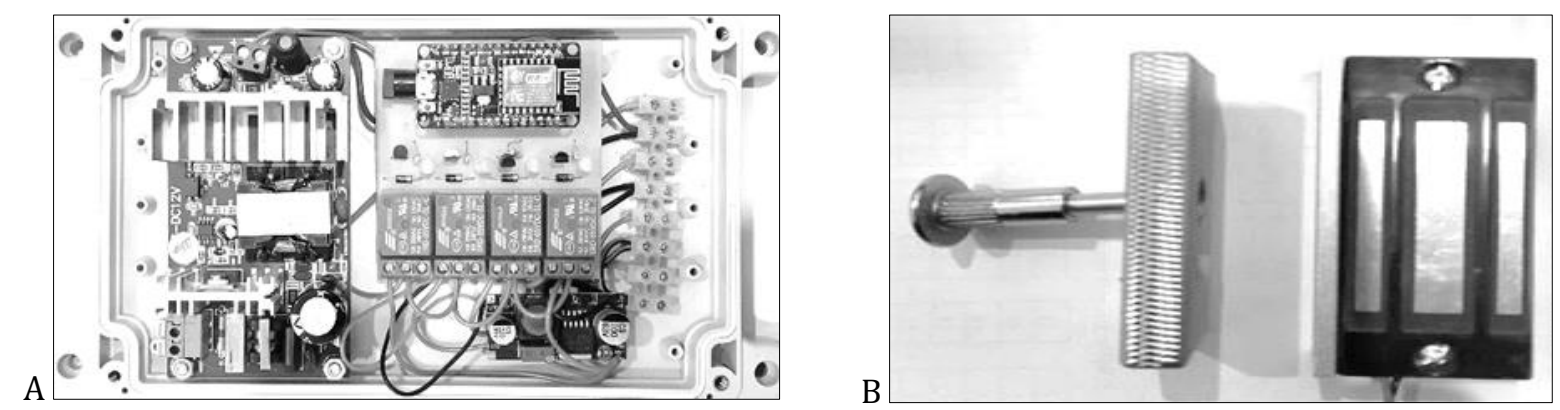

Figure 3 Electromagnetic lock latch and control system

\subsection{System operation}

The system is powered, block 1 will broadcast to grant IP to desktop computers, laptops or smartphones if block 1 is configured to allocate IPs and concurrently pair with Wi-Fi Router system if Internet connection is allowed or block 1 will receive IP when connecting to Wi-Fi Router and be considered equal to computer/laptop, specifically:

Block 1 (ESP8266 node MCU) is programmed to create a web server with Wi-Fi broadcasting function connecting desktop/laptop and smartphone. 
- Devices such as laptops will be able to log into the web server through the IP address set up and the network's secure account with WPA2.

- Users using laptops log into the system via a web browser with connection port 80 or port 443 to open the control interface to open and close the lab door.

- Users can use the app built specifically for Android to access the application or open the web interface to control the opening and closing of the Lab door.

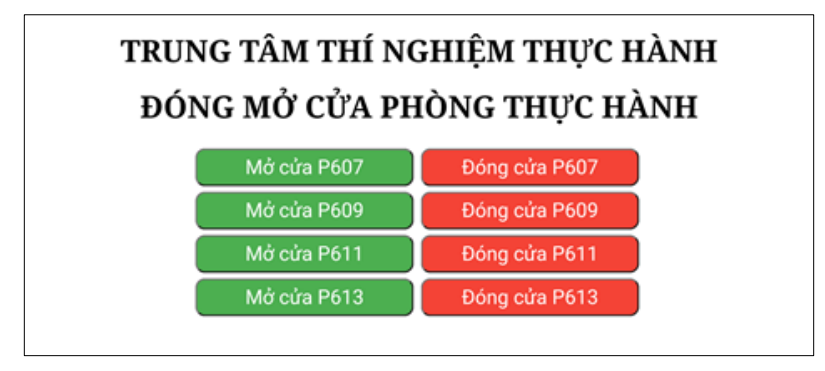

Figure 4 Door opening and closing interface on computers and Smart phones

\section{Experimental results}

The test system is assessed. Value of benefits obtained are:

- The door opening and closing system is tested with the utility of opening and closing doors for the practical labs with low investment costs and a synchronous system when designed and installed for many practical labs

- Users are not afraid to forget to lock the door and have to go to check the many practical labs, especially reducing the wait for lecturers and students when coming to the practical labs.

- To gradually modernize the management of the practical labs on the basis of technology mastery;

- The product is tested at the practical laboratory center.

- Apply to school and office lab systems.

\section{Conclusion}

The system of monitoring and opening and closing doors remotely via the network will bring benefits such as reducing labor in the management and operation of practical labs in practical laboratory centers, libraries, and offices. The system is combined with security cameras and alarms to help manage and monitor remotely effectively and conveniently for users.

\section{Compliance with ethical standards}

\section{Acknowledgments}

The author gratefully acknowledges the Posts and Telecommunications Institute of Technology, Vietnam for supporting this work.

\section{Disclosure of conflict of interest}

The author declares that they have no conflicts of interest.

\section{References}

[1] Aiswarya IP. A Survey on Smart Door Lock Security Methodologies Implemented Using Various Wireless Access Technologies, International Research Journal of Modernization in Engineering Technology and Science. 2020; 02(09): 1814-1819.

[2] Ketan Rathod, Rambabu Vatti, Mandar Nandre, Sanket Yenare. Smart Door Security Using Arduino and Bluetooth Application, International Journal of Current Engineering and Scientific Research. 2017; 4(11): 73-77.

[3] Nayana, Shashidhar. Smart Door Lock System, International Journal for Modern Trends in Science and Technology. February 2019; 05(02): 36-38. 
[4] Tai, Tuyen Nguyen. Smart Sensors in Automatic Power on Off for Projector Based on User Monitoring Signals, International Journal of Research in Engineering and Science. 2016; 51-55.

[5] Yogendra Singh Parihar. A Review of Use of Node MCU Esp8266 in IoT Products, Journal of Emerging Technologies and Innovative Research. June 2019; 6(6): 1085-1088.

[6] https://www.make-it.ca/nodemcu-details-specifications/. 